\title{
Article \\ Efficient Sulfate Adsorption on Modified Adsorbents Prepared from Zea mays Stems
}

\author{
Candelaria Tejada-Tovar ${ }^{1}$, Ángel Villabona-Ortíz ${ }^{1}$, Angel Dario Gonzalez-Delgado ${ }^{2, * \mathbb{D}}$, Adriana Herrera ${ }^{2}$ and \\ Andrea Viera De la Voz ${ }^{1}$
}

check for updates

Citation: Tejada-Tovar, C.;

Villabona-Ortíz, Á.; Gonzalez-Delgado, A.D.; Herrera, A.; Viera De la Voz, A. Efficient Sulfate Adsorption on Modified Adsorbents Prepared from Zea mays Stems. Appl. Sci. 2021, 11, 1596. https://doi.org/10.3390/ app11041596

Received: 1 January 2021

Accepted: 3 February 2021

Published: 10 February 2021

Publisher's Note: MDPI stays neutral with regard to jurisdictional claims in published maps and institutional affiliations.

Copyright: (c) 2021 by the authors. Licensee MDPI, Basel, Switzerland. This article is an open access article distributed under the terms and conditions of the Creative Commons Attribution (CC BY) license (https:/ / creativecommons.org/licenses/by/ $4.0 /)$.
1 Process Design and Biomass Utilization Research Group (IDAB), Chemical Engineering Department, Universidad de Cartagena, Avenida del Consulado St. 30, Cartagena de Indias 130015, Colombia; ctejadat@unicartagena.edu.co (C.T.-T.); avillabonao@unicartagena.edu.co (Á.V.-O.); avierad@unicartagena.edu.co (A.V.D.1.V.)

2 Nanomaterials and Computer Aided Process Engineering Research Group (NIPAC), Chemical Engineering Department, Universidad de Cartagena, Avenida del Consulado St. 30, Cartagena de Indias 130015, Colombia; aherrerab2@unicartagena.edu.co

* Correspondence: agonzalezd1@unicartagena.edu.co

\begin{abstract}
The effect of temperature on the sulfate adsorption capacity of adsorbents prepared from corn stalks (Zea mays) was evaluated. Two bioadsorbents were prepared from biomass: a biochar modified with $\mathrm{H}_{2} \mathrm{SO}_{4}$ with mass: volume ratio 1:1 (B 1:1), and cellulose modified with cetyl trimethyl ammonium chloride (CTAC). There were also determined thermodynamic parameters $\left(\Delta \mathrm{G}^{\circ}, \Delta \mathrm{S}^{\circ}\right.$ and $\left.\Delta \mathrm{H}^{\circ}\right)$ and it was studied the adsorption kinetics and isotherm. At $25{ }^{\circ} \mathrm{C}$ was obtained the highest adsorption capacity of 16.4 and $7.4 \mathrm{mg} / \mathrm{g}$ with mass/volume ratio B 1:1 and modified corn (MC) respectively; it was observed an adverse effect of temperature increase on bioadsorbents' performance. The thermodynamic parameters showed that the adsorption process is exothermic, not spontaneous, and it was given by chemisorption. Adsorption kinetics showed that equilibrium was reached at $420 \mathrm{~min}$ and that the pseudo-second-order model adjusted the experimental data with $\mathrm{R}^{2}>0.98$ and $\mathrm{q}_{\mathrm{e}}$ of 16.64 and $7.48 \mathrm{mg} / \mathrm{g}$ for B 1:1 as well as MC. The adsorption isotherm showed a good fit to Freundlich's model when using B 1:1, whereas using MC as adsorbents the data was adjusted by Dubinin-Radushkevich's model. Zea mays stems are an abundant agricultural residue and are a good source for the preparation of biochar type bioadsorbents as well as the extraction of cellulose, its use is recommended in the removal of sulfates in solution.
\end{abstract}

Keywords: biochar; adsorption kinetics; sulphate ions; corn; cellulose modification

\section{Introduction}

Sulfate ions appear in surface and ground water. The main sources of sulfate in natural water are chemical weathering and the oxidation processes of sulfur-containing minerals [1]. However, their concentration in water bodies has been increasing over time, due to the discharge of industrial effluents such as those from acid mine drainage, pharmaceutical wastewater, printing and dyeing [2]. Although the sulfate ion is often considered nontoxic, high concentrations of sulfate ions in water can cause an imbalance in the natural sulfur cycle in the ecosystem and endanger human health with prolonged ingestion, causing a laxative effect, dehydration and gastrointestinal irritation [3]. Therefore, the sulfate ion needs to be removed from any wastewater before it is discharged into the surrounding environment.

Several physical, biological and chemical processes have been investigated for the removal of sulfates dissolved in water and wastewater. These processes include adsorption [4], electrocoagulation [5], ion exchange [6], chemical precipitation [7], coagulation, crystallization, membrane filtration and reverse osmosis [8]. Adsorption removal is widely used due to its capacity for fast and effective removal. The adsorbent plays an important role in determining the effectiveness of the adsorption technology. Ideally, the desired adsorbent should be of low cost, have high adsorption capacity and be renewable [9]. 
Adsorbents of lignocellulosic origin have been traditionally implemented in adsorption processes. However, a few adsorbents derived from cornstalks have been implemented in the removal of anions [10,11], and these adsorbents have been studied in terms of the kinetic and equilibrium study of adsorption, as well as thermodynamic analysis. The study of the adsorption rate also plays an important role in the implementation of adsorption technology for contaminant removal, since rapid adsorption is ideal, in order to reduce the cost of wastewater treatment and the consumption of time and energy entailed [12]. The adjustment to the kinetics models has contributed to the understanding of the process mechanism [13]. Isothermic study has helped to determine the affinity and interactions between the contaminants and adsorbent's active centers [14]. Numerical modelling based on thermodynamics provides an economical and accurate tool for studying the adsorption process, its costs and the effects of important parameters [15]. Therefore, this study focused on the evaluation of the effects of temperature on the adsorption capacity of sulfates in adsorbents prepared from cornstalks (Zea mays). Two bioadsorbents were prepared from biomass: a biochar modified with $\mathrm{H}_{2} \mathrm{SO}_{4}$ at a mass/volume ratio of 1:1 (B 1:1) and cellulose modified with cetyl trimethyl ammonium chloride (CTAC). Their thermodynamic parameters $\left(\Delta \mathrm{G}^{\circ}, \Delta \mathrm{S}^{\circ}\right.$ and $\left.\Delta \mathrm{H}^{\circ}\right)$ were determined, and the corresponding adsorption kinetics and isotherms were studied. This study also examined the kinetics and equilibrium of sulfate anion adsorption on the prepared bioadsorbents.

\section{Materials and Methods}

\subsection{Materials}

To prepare the synthetic sulfate solution, analytical grade potassium sulfate $\left(\mathrm{K}_{2} \mathrm{SO}_{4}\right)$, Merck Millipore brand with $95 \%$ purity, was used as a reagent. Cellulose modification was carried out with $25 \%$ methyl trimethyl ammonium chloride (MTAC), and the biocarbons were activated with $98 \%$ sulfuric acid $\left(\mathrm{H}_{2} \mathrm{SO}_{4}\right)$. A Biobase UV/Vis spectrophotometer model BK-UV1900 was used to determine the final contaminant concentration.

\subsection{Biomass Pretreatment}

Raw cornstalks (RCSs) were collected as postharvest waste from a village in Bolivar, Colombia. Biomass in better condition was selected to guarantee its properties. The cornstalks were then washed with deionized water, dried in an oven for $12 \mathrm{~h}$ at $60^{\circ} \mathrm{C}$ and then ground in an electric mill. Sizes between 1 and $2 \mathrm{~mm}$ were selected in a shaker-type sieve.

\subsection{Preparation of Bioadsorbents}

The pretreated cornstalks were impregnated with $50 \mathrm{~g}$ of pretreated biomass with $50 \%$ $\mathrm{H}_{2} \mathrm{SO}_{4}$ in a 1:1 weight-to-volume ratio (B 1:1) for $24 \mathrm{~h}$ at room temperature $\left(30^{\circ} \mathrm{C}\right)$. Subsequently, the mixture was carbonized in a muffle oven at $520^{\circ} \mathrm{C}$ for $30 \mathrm{~min}$ with a $10^{\circ} \mathrm{C} / \mathrm{min} \mathrm{ramp}$. The biochar obtained was washed with abundant distilled water up to neutral $\mathrm{pH}$, dried at $100{ }^{\circ} \mathrm{C}$ for $8 \mathrm{~h}$ and stored in airtight containers until its use in the adsorption tests [16]. At the end of the process, a yield of $70 \%$ was obtained, with $15 \mathrm{~g}$ of $\mathrm{B} 1: 1$.

For the preparation of the modified cellulose, sizes smaller than $0.14 \mathrm{~mm}$ were initially selected. Then, the cellulose was extracted by placing $20 \mathrm{~g}$ of the cornstalks in contact with distilled water with mechanical agitation for $10 \mathrm{~min}$. The mixture was filtered, the supernatant was discarded and $500 \mathrm{~mL}$ of $4 \% \mathrm{NaOH}$ solution was added and agitated at $200 \mathrm{rpm}$ at $80^{\circ} \mathrm{C}$ for $2 \mathrm{~h}$. The solid sample obtained was washed, treated with $\mathrm{NaOH}$ and washed again until the washing water was clear. The cellulose was dried to a constant mass at room temperature. A solution with $50 \mathrm{~g}$ of $\mathrm{NaCl}, 500 \mathrm{~mL}$ of distilled water and $50 \mathrm{~mL}$ of acid was then added. The mixture was stirred for $24 \mathrm{~h}$ at $30^{\circ} \mathrm{C}$ and then decanted. The solid obtained was cellulose, which was dried for $3 \mathrm{~h}$ at $60^{\circ} \mathrm{C}$ [17]. The cellulose was modified by adding $62.8 \mathrm{~mL}$ of cetyl trimethyl ammonium chloride (CTAC) at $100 \mathrm{mmol} / \mathrm{L}$, using magnetic agitation at $250 \mathrm{rpm}$ for $24 \mathrm{~h}$ at $27^{\circ} \mathrm{C}$ [18]. The process is summarized in Figure 1. 


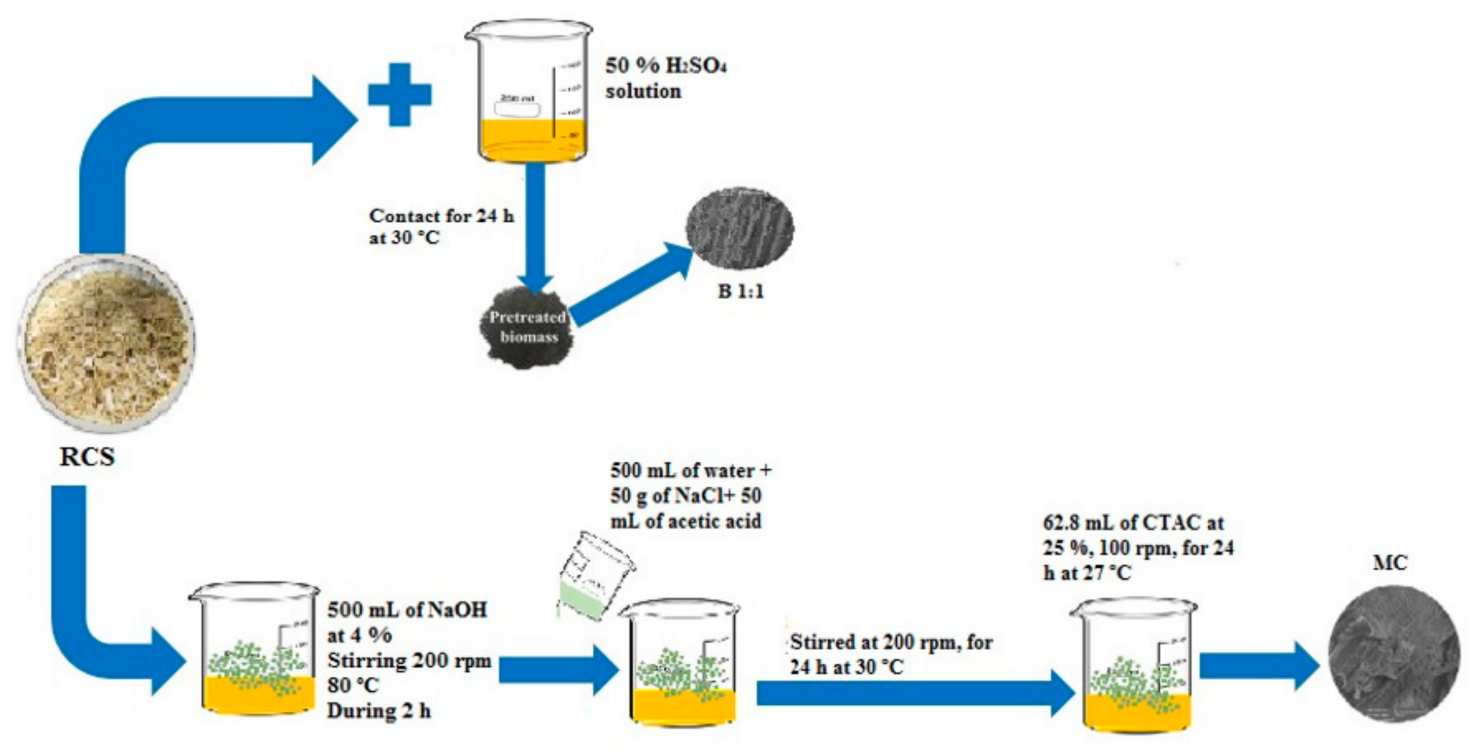

Figure 1. Mechanism of biochar modified with $\mathrm{H}_{2} \mathrm{SO}_{4}$ at a mass/volume ratio of 1:1 (B 1:1) and modified corn (MC) bioadsorbent preparation process.

\subsection{Adsorption Tests}

The sulfate solution was prepared by dissolving $0.1479 \mathrm{~g}$ of dehydrated $\mathrm{Na}_{2} \mathrm{SO}_{4}$ in $1 \mathrm{~L}$ of distilled water according to the ASTM D 560-60 [19]. The experiments were conducted by placing $5 \mathrm{~mL}$ of contaminated solution in contact with $0.01 \mathrm{~g}$ of adsorbent at $200 \mathrm{rpm}$ in an orbital shaker at different temperatures $\left(25,30,35,40\right.$ and $\left.45^{\circ} \mathrm{C}\right)$. Sulfate anion detection was performed by UV/Vis spectrometry at $420 \mathrm{~nm}$. The adsorption capacity $\left(\mathrm{q}_{\mathrm{e}}\right)$ was determined using Equation (1):

$$
q_{e}\left(\frac{m g}{g}\right)=\frac{\left(C_{0}-C_{e}\right) * V}{m}
$$

where $C_{0}$ and $C_{e}$ represent the initial concentration of anions in the solutions and the concentration in equilibrium after the adsorption process, both expressed in $\mathrm{mg} / \mathrm{L} . V$ is the volume of the solution in $\mathrm{L}$, and $m$ the amount of adsorbent in $g$.

\subsection{Thermodynamic Parameters}

The thermodynamic parameters, namely Gibbs free energy $\left(\Delta \mathrm{G}^{\circ}\right)$, enthalpy change $\left(\Delta \mathrm{H}^{\circ}\right)$ and entropy change $\left(\Delta \mathrm{S}^{\circ}\right)$, were determined by Van't Hoff's graphical method (Equations (2) and (3)) and used to examine the nature of the adsorption and its thermodynamic behavior [20].

$$
\begin{aligned}
\Delta G^{\circ} & =-R T \operatorname{Ln}(K c) \\
\operatorname{Ln} K_{C} & =\frac{-\Delta H^{\circ}}{R T}+\frac{{ }^{\circ} \Delta S}{R}
\end{aligned}
$$

where $R$ is the ideal gas constant and has a value of $8314 \mathrm{~J} / \mathrm{mol} \mathrm{K,T}$ is the temperature expressed in kelvin and $K_{c}$ is the adsorption equilibrium constant.

\subsection{Kinetics and Isotherms of Adsorption}

Kinetics was studied to determine the saturation time of the adsorbent and the mechanisms that control the adsorption process [21]. Kinetic experiments were carried out at the best temperature condition at $100 \mathrm{mg} / \mathrm{L}$ using adsorbent doses of $2 \mathrm{~g} / \mathrm{L}$ in $100 \mathrm{~mL}$ solution, $\mathrm{pH}$ 4, at $200 \mathrm{rpm}$ agitation. Samples were taken at 5, 10, 20, 30, 60, 180, 300, 420 and $1440 \mathrm{~min}$ for each assay. The pseudo-first-order (Equation (4)), pseudo-second-order 
(Equation (5)) and Elovich (Equation (6)) models were adjusted to analyze the experimental kinetic data; their equations and parameters are summarized in Table 1.

Table 1. Kinetic adsorption models [22].

\begin{tabular}{|c|c|c|c|}
\hline Model & Equation & & Parameters \\
\hline Pseudo-first order & $\mathrm{q}_{\mathrm{t}}=\mathrm{q}_{\mathrm{e}}\left(1-\mathrm{e}^{-\mathrm{k}_{1} \mathrm{t}}\right)$ & (4) & $\begin{array}{l}\mathrm{k}_{1}\left(\mathrm{~min}^{-1}\right) \text { : Lagergren's constant } \\
\mathrm{q}_{\mathrm{e}}(\mathrm{mg} / \mathrm{g}) \text { : amount of contaminant adsorbed } \\
\text { per unit mass in the equilibrium } \\
\mathrm{q}_{\mathrm{t}}(\mathrm{mg} / \mathrm{g}) \text { : amount of contaminant adsorbed } \\
\text { per unit of mass at any time } \mathrm{t} \\
\mathrm{t}(\mathrm{min}) \text { : time }\end{array}$ \\
\hline Pseudo-second order & $\mathrm{q}_{\mathrm{t}}=\frac{\mathrm{t}}{\frac{1}{\mathrm{k}_{2} * \mathrm{q}_{\mathrm{e}}^{2}}+\frac{\mathrm{t}}{\mathrm{q}_{\mathrm{e}}}}$ & (5) & $\begin{array}{l}\mathrm{k}_{2}\left(\mathrm{~g} \mathrm{mmol}^{-1} \mathrm{~min}^{-1}\right) \text { : second-order reaction } \\
\text { speed coefficient } \\
\mathrm{q}_{\mathrm{e}}(\mathrm{mg} / \mathrm{g}) \text { : amount of contaminant adsorbed } \\
\text { per unit mass in the equilibrium } \\
\mathrm{q}_{\mathrm{t}}(\mathrm{mg} / \mathrm{g}) \text { : amount of contaminant adsorbed } \\
\text { per unit of mass at any time } \mathrm{t} \\
\mathrm{t} \text { (min): time }\end{array}$ \\
\hline Elovich & $\mathrm{q}_{\mathrm{t}}=\frac{1}{\beta} * \ln (\alpha \beta)+\frac{1}{\beta} * \ln (\mathrm{t})$ & (6) & $\begin{array}{l}\alpha\left(\mathrm{mg} \mathrm{g}^{-1} \min ^{-1}\right) \text { : initial adsorption rate } \\
\beta\left(\mathrm{g} \mathrm{mg}^{-1}\right): \text { desorption constant related to } \\
\text { surface range and activation energy for } \\
\text { chemisorption } \\
\mathrm{q}_{\mathrm{t}}(\mathrm{mg} / \mathrm{g}) \text { representing the amount of } \\
\text { chemisorption gas in a time } \mathrm{t} \\
\mathrm{t}(\mathrm{min}) \text { : time }\end{array}$ \\
\hline
\end{tabular}

The isotherms were studied to describe the phenomena responsible for the process and to represent the amount of solute adsorbed per unit mass in the equilibrium as the initial concentration varies [23]. The experiments were carried out by placing $2 \mathrm{~g} / \mathrm{L}$ of adsorbent in contact with $100 \mathrm{~mL}$ of the solution of the anions at different concentrations, namely 20, 40, 60, 80 and $100 \mathrm{mg} / \mathrm{L}$, for $24 \mathrm{~h}$. The models of Langmuir (Equation (7)), Freundlich (Equation (8)) and Dubinin-Radushkevich (Equation (10)), were adjusted to the experimental data by nonlinear regression in the OriginPro8 software. The equations and parameters are summarized in Table 2. 
Table 2. Isothermal models [10].

\begin{tabular}{|c|c|c|c|}
\hline Model & Equation & & Parameters \\
\hline Langmuir & $\mathrm{q}_{\mathrm{e}}=\frac{\mathrm{q}_{\max } \mathrm{K}_{\mathrm{L}} \mathrm{C}_{\mathrm{e}}}{1+\mathrm{K}_{\mathrm{L}} \mathrm{C}_{\mathrm{e}}}$ & (7) & $\begin{array}{l}\mathrm{C}_{\mathrm{e}}(\mathrm{mg} / \mathrm{L}) \text { : concentration of adsorbate in the equilibrium } \\
\mathrm{q}_{\mathrm{e}}(\mathrm{mg} / \mathrm{g}) \text { amount of adsorbate adsorbed per gram of adsorbent at } \\
\text { equilibrium } \mathrm{Q}_{\max }(\mathrm{mg} / \mathrm{g}) \text { : coverage capacity in the monolayer } \\
\text { KL: Langmuir isothermal constant }\end{array}$ \\
\hline Freundlich & $\mathrm{q}_{\mathrm{e}}=\mathrm{K}_{\mathrm{F}} \mathrm{C}_{\mathrm{e}}^{1 / 2}$ & (8) & $\begin{array}{l}\mathrm{q}_{\mathrm{e}}(\mathrm{mg} / \mathrm{g}) \text { : amount of adsorbate adsorbed per gram of adsorbent at } \\
\text { equilibrium } \\
\mathrm{K}_{\mathrm{F}}(\mathrm{L} / \mathrm{g}) \text { : Freundlich's isothermal constant, } \mathrm{C}_{\mathrm{e}}(\mathrm{mg} / \mathrm{L}) \text { : equilibrium } \\
\text { adsorbate concentration }\end{array}$ \\
\hline \multirow{3}{*}{ Dubinin-Radushkevich } & $\mathrm{q}_{\mathrm{e}}=\mathrm{q}_{\mathrm{DR}} * \mathrm{e}^{-\mathrm{K}_{\mathrm{DR}} \varepsilon^{2}}$ & (9) & \multirow{3}{*}{$\begin{array}{l}\varepsilon^{2}: \text { potential of Polanyi, which is based on temperature } \\
\mathrm{K}_{\mathrm{DR}}\left(\mathrm{mol}^{2} / \mathrm{kJ}^{2}\right) \text { : Dubinin-Radushkevich's constant related to } \\
\text { adsorption energy } \\
\mathrm{E}(\mathrm{KJ} / \mathrm{mol}) \text { : the average adsorption energy per molecule of } \\
\text { adsorbate required to transfer one mole of the ion from the solution } \\
\text { to the surface of the adsorbent }\end{array}$} \\
\hline & $\varepsilon=\mathrm{RT} * \ln \left(1+\frac{1}{\mathrm{C}_{\mathrm{e}}}\right)$ & (10) & \\
\hline & $\mathrm{E}=\frac{1}{\sqrt{2 \mathrm{~K}_{\mathrm{DR}}}}$ & (11) & \\
\hline
\end{tabular}

\section{Results}

\subsection{Characterization of RCSs and MC}

The elemental content variations of raw and modified corn (RCSs and MC, respectively) are shown in Table 3. In the RCS sample, the contents of nitrogen, carbon and hydrogen were $1.35 \%, 41.38 \%$ and $6.34 \%$, respectively. After the treatment with CTAC, the contents of three elements in MC increased significantly. In particular, the nitrogen content reached $6.34 \%$, confirming that related functional groups (amine groups) were successfully loaded onto the cellulose molecules in the modification process. These results are similar to those reported by Fan and Zhang [24] in their modification of cellulose from cornstalks with epichlorohydrin, N, N-dimethylformamide, pyridine and diethylamine.

Table 3. Elemental content of raw cornstalk (RCS) and modified corn (MC) samples.

\begin{tabular}{ccc}
\hline & RCS & MC \\
\hline $\mathrm{N}(\%)$ & 1.35 & 6.34 \\
$\mathrm{C}(\%)$ & 41.38 & 52.17 \\
$\mathrm{H}(\%)$ & 6.27 & 6.93 \\
\hline
\end{tabular}

\subsection{Effect of Temperature}

The zero $\mathrm{pH}$ loading point $\left(\mathrm{pH}_{\mathrm{PZC}}\right)$ was established to determine the ideal $\mathrm{pH}$ for anion adsorption, as the exposed surface of a bioadsorbent is protonated at $\mathrm{pH}$ values below the $\mathrm{pH}_{\mathrm{PZC}}$ [21]. The $\mathrm{pH}_{\mathrm{PZC}}$ of the $\mathrm{B} 1: 1$ was 5.17 and that of the $\mathrm{MC}$ was 6 . Therefore, to guarantee the protonation of the surface of the biomaterial, the working $\mathrm{pH}$ of 4 was selected for use in the adsorption tests using the B 1:1 and the MC.

The bioadsorption tests were performed at $\mathrm{pH} 4$, initial concentration of $100 \mathrm{mg} / \mathrm{L}$ and adsorbent dose of $2 \mathrm{~g} / \mathrm{L}$, varying the temperature between 25 and $45^{\circ} \mathrm{C}$. Figure 2 shows the effects of temperature on sulfate adsorption capacity of B 1:1 and MC. The results showed that a temperature of $25^{\circ} \mathrm{C}$ resulted in the best behavior of the adsorbents in the removal of the anion, and B 1:1 presented the best performance. Consequently, as the temperature increased, the adsorption capacity of the adsorbents decreased, which could be due to the exothermic nature of the process, as similarly reported for the removal of sulfates on quaternized cellulose [25]. 


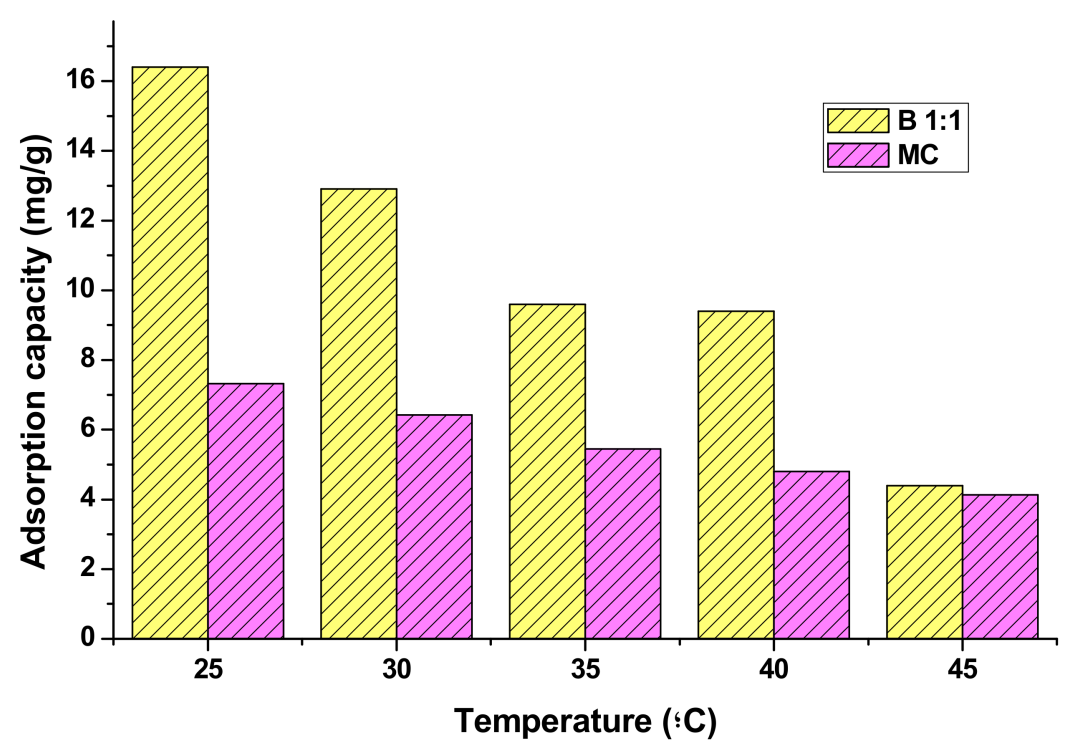

Figure 2. Effect of temperature on sulfate adsorption capacity using B 1:1 and MC.

The thermodynamic parameters, namely $\Delta \mathrm{H}^{\circ}, \Delta \mathrm{S}^{\circ}$ and $\Delta \mathrm{G}^{\circ}$, were calculated using Van't Hoff's method, and the results are summarized in Table 4 . The negative values of $\Delta \mathrm{H}^{\circ}$ indicate that the process is exothermic, as shown by the results presented in Figure 1, which demonstrates that the application of energy to the system is not required for the reactions to occur [26]. The value of $\Delta \mathrm{H}^{\circ}$ was higher for $\mathrm{B} 1: 1$, which explains the greater exothermic character of the reactions on the biochar. This would explain the decrease of the capacity of adsorption of B 1:1 as the temperature increased up to $45^{\circ} \mathrm{C}$. The decrease of the adsorption capacity as the temperature increased could result from the weakening of the interaction of forces between the adsorbate and the adsorbent due to the increase in the energy of the system [27].

Table 4. Thermodynamic parameters of sulfate adsorption.

\begin{tabular}{ccccc}
\hline Adsorbent & $\mathbf{T}(\mathbf{K})$ & $\left.\boldsymbol{\Delta G}^{\circ} \mathbf{( K J} / \mathbf{m o l}\right)$ & $\left.\boldsymbol{\Delta H}^{\circ} \mathbf{( K J} / \mathbf{m o l} \cdot \mathbf{K}\right)$ & $\left.\boldsymbol{\Delta S}^{\circ} \mathbf{( K J} / \mathbf{m o l}\right)$ \\
\hline & 298 & 9.197 & -57.359 & -0.223 \\
B 1:1 & 303 & 10.313 & - & \\
& 308 & 11.429 & - & \\
& 313 & 12.546 & & -0.1256 \\
& 318 & 13.662 & & \\
MC & 298 & 11.8795 & -25.5705 & \\
& 303 & 12.5075 & & \\
& 308 & 13.1355 & & \\
\hline
\end{tabular}

The positive value of $\Delta \mathrm{G}^{\circ}$ shows that the system is not spontaneous, and the increase in its value indicates that the system loses spontaneity as the temperature increases, indicating that agitation is necessary [16]. The negative entropy value indicates the associative process of sulfate adsorption over B 1:1 and MC, which shows that the existing particles in the solution were smaller after the adsorption process, demonstrating that the process takes place by chemisorption [28].

\subsection{Adsorption Kinetics}

The effect of time on the adsorbent removal capacity (Figure 3) was assessed to determine the possible mechanisms involved in the adsorption process [29]. It was found 
that anion uptake happened quickly in the first few minutes of the process and gradually decreased until equilibrium was reached. This phenomenon occurred due to the availability of free active sites of adsorption for sulfate retention, which are occupied as the contact time passes [1]. Equilibrium was reached at about $420 \mathrm{~min}$ for the two adsorbents, with better performance of B 1:1, which could be due to surface protonation as a result of its modification with sulfuric acid [30].

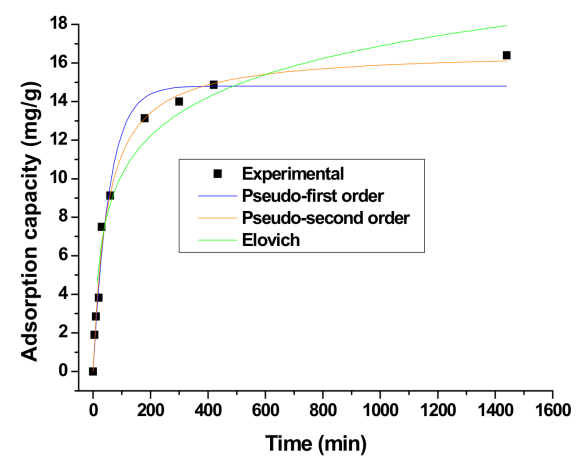

(a)

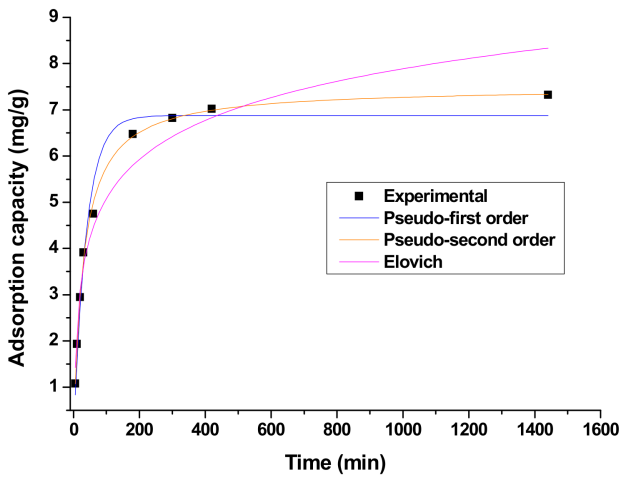

(b)

Figure 3. Sulfate adsorption kinetics for (a) B 1:1 and (b) MC.

The experimental data were fitted to the pseudo-first-order, pseudo-second-order and Elovich models by nonlinear regression, and the fitting parameters are summarized in Table 5.

Table 5. Adjustment parameters of sulfate adsorption kinetics.

\begin{tabular}{cccc}
\hline Model & Parameters & MC & B 1:1 \\
\hline \multirow{3}{*}{ Pseudo-first order } & $\mathrm{q}_{\mathrm{e}}\left(\mathrm{mg}^{-\mathrm{g}}\right)$ & 6.8739 & 14.801 \\
& $\mathrm{k}_{1}\left(\mathrm{~min}^{-1}\right)$ & 0.0258 & 0.018 \\
& $\mathrm{SE}$ & 0.19820 & 0.5168 \\
& $\mathrm{R}^{2}$ & 0.9730 & 0.966 \\
\hline \multirow{3}{*}{ Pseudo-second order } & $\mathrm{q}_{\mathrm{e}}(\mathrm{mg} / \mathrm{g})$ & 7.4891 & 16.646 \\
& $\mathrm{k}_{2}(\mathrm{~g} / \mathrm{mg} \cdot \mathrm{min})$ & 0.0045 & 0.0013 \\
& $\mathrm{SE}$ & 0.0764 & 0.4291 \\
& $\mathrm{R}^{2}$ & 0.9975 & 0.988 \\
\hline \multirow{2}{*}{ Elovich } & $\alpha(\mathrm{mg} / \mathrm{g} \cdot \mathrm{min})$ & 0.7856 & 0.976 \\
& $\beta(\mathrm{g} / \mathrm{mg})$ & 0.9199 & 0.976 \\
& $\mathrm{SE}$ & 0.2935 & 0.2113 \\
& $\mathrm{R}^{2}$ & 0.9455 & 0.959 \\
\hline
\end{tabular}

The kinetics of sulfate adsorption over B 1:1 and MC is described by the pseudosecond-order model, whose correlation coefficient $\left(\mathrm{R}^{2}\right)$ is closer to 1.0 , and the equilibrium adsorption quantities calculated are much closer to the experimental values. This suggests that the mechanism by which adsorption occurs is chemical, in which the speed of adsorption is limited by valence forces given by the exchange of electrons between the adsorbate and the adsorbent [24], and that the limiting step is chemisorption due to physicochemical interactions between the two phases [31], as evidenced by the thermodynamic parameters (Table 2). A previous study also showed that sulfate adsorption follows the pseudo-second-order model [9].

\subsection{Adsorption Equilibrium}

The sulfate adsorption isotherms over B 1:1 and MC are represented in Figure 4, and the experimental data were adjusted with the Langmuir, Freundlich and Dubinin- 
Radushkevich equations (Table 6). The sulfate adsorption isotherm over B 1:1 rose very rapidly as concentrations increased (Figure 3a), indicating a high affinity of part of the bioadsorbent for the anion. When using MC, the adsorption capacity increased at lower sulfate concentrations. However, as the sulfate concentration in solution increased, the amount of sulfate adsorbed reached a limit value and decreased. The behavior of MC suggested that there is a strong affinity between sulfate ions and adsorbent, although it showed worse performance than B 1:1 [4].

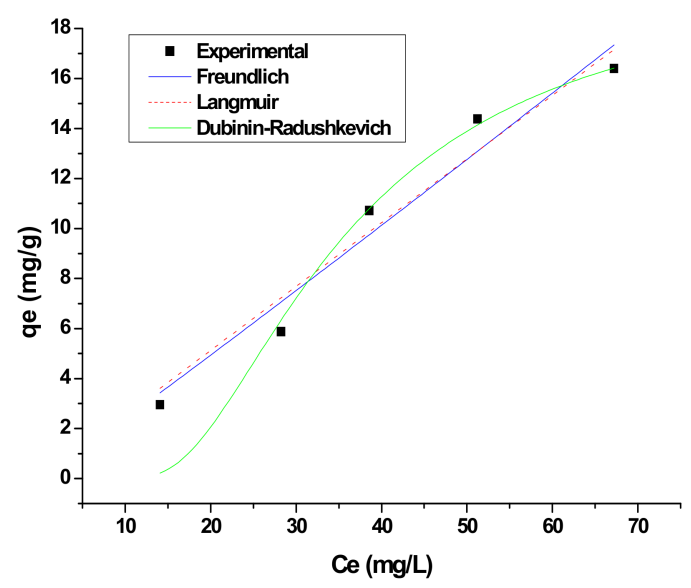

(a)

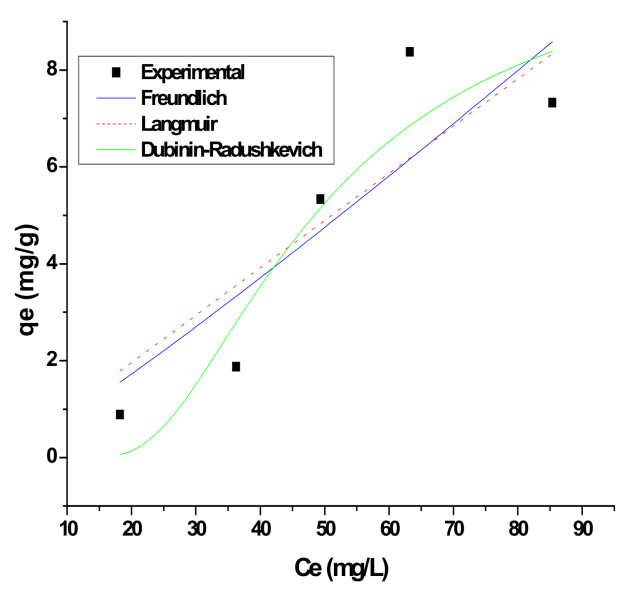

(b)

Figure 4. Isothermal sulfate adsorption on (a) B 1:1 and (b) MC.

Table 6. Adjustment parameters of sulfate adsorption isotherms.

\begin{tabular}{cccc}
\hline Model & Parameter & B 1:1 & MC \\
\hline \multirow{3}{*}{ Langmuir } & $\mathrm{q}_{\max }(\mathrm{mg} / \mathrm{g})$ & 29.514 & 19.779 \\
& $\mathrm{~K}_{\mathrm{L}}(\mathrm{L} / \mathrm{mg})$ & $9.06 \times 10^{-5}$ & $5.16 \times 10^{-5}$ \\
& $\mathrm{SE}$ & 0.2937 & 0.5165 \\
& $\mathrm{R}^{2}$ & 0.945 & 0.7014 \\
\hline \multirow{2}{*}{ Freundlich } & $\mathrm{Kf}(\mathrm{mg} / \mathrm{g})$ & 0.221 & 0.0627 \\
& $\mathrm{n}$ & 0.965 & 0.9041 \\
& $\mathrm{SE}$ & 1.139 & 2.9381 \\
& $\mathrm{R}^{2}$ & 0.946 & 0.7081 \\
\hline \multirow{5}{*}{ Dubinin-Radushkevich } & $\mathrm{q}_{\mathrm{DR}}(\mathrm{mg} / \mathrm{g})$ & 20.247 & 10.7359 \\
& $\mathrm{~K}_{\mathrm{DR}}\left(\mathrm{mol}^{2} / \mathrm{kJ}^{2}\right)$ & $1.29 \times 10^{-4}$ & $2.4493 \times 10^{-4}$ \\
& $\mathrm{E}(\mathrm{KJ} / \mathrm{mol})$ & 62.257 & 45.1819 \\
& $\mathrm{SE}$ & 2.4117 & 2.1699 \\
& $\mathrm{R}^{2}$ & 0.919 & 0.8465 \\
\hline
\end{tabular}

According to the standard error (SE) and $\mathrm{R}^{2}$ values, Dubinin-Radushkevich's model fits the data better when using MC. Since the E value is higher than $8 \mathrm{KJ} / \mathrm{mol}$, it can be concluded that the process is controlled by chemisorption with strong interactions between the active centers and the anion [32], as evidenced by the calculation of thermodynamic parameters (Table 3). Based on the fit to Dubinin-Radushkevich's model, it can be assumed that the bioadsorbent presents a heterogeneous structure [33]. Using B 1:1, it was found that Freundlich's model describes the adsorption equilibrium, indicating that the process occurs in multilayers on the surface of the bioadsorbent due to its heterogeneity [10]. 


\section{Conclusions}

The conclusions of this study are as follows: (i) Zea mays stems are a good source for the preparation of bioadsorbent-type biochar as well as the extraction of cellulose. (ii) An evaluation of the effects of temperature showed that the highest adsorption capacity (16.4 mg/g and $7.3 \mathrm{mg} / \mathrm{g}$ for B 1:1 and MC, respectively) was obtained at $25^{\circ} \mathrm{C}$, and the increase in temperature had an adverse effect on the performance of the bioadsorbents. (iii) The thermodynamic parameters showed that the adsorption process is exothermic and not spontaneous and that it occurs by chemisorption. (iv) A better performance of B 1:1 was indicated, which could be due to the protonation of the bioadsorbent and the bivalent nature of the anion. (v) Adsorption kinetics showed that equilibrium was reached at $420 \mathrm{~min}$ and that the pseudo-second-order model adjusted the experimental data. (vi) The adsorption equilibrium determined that Freundlich's model adjusted the removal data for B 1:1, indicating that the process is multilayered. However, Dubinin-Radushkevich's model adjusted the adsorption data for MC, establishing that the mechanism that controls the process is chemisorption with strong interactions between the active centers and the anion.

Author Contributions: Conceptualization, C.T.-T., Á.V.-O. and A.D.G.-D.; methodology, C.T.-T.; software, Á.V.-O.; validation, C.T.-T., Á.V.-O., A.H. and A.D.G.-D.; formal analysis, A.H.; investigation, A.V.D.l.V.; resources, C.T.-T.; data curation, A.D.G.-D.; writing—original draft preparation, A.V.D.1.V.; writing-review and editing, C.T.-T.; visualization, Á.V.-O.; supervision, C.T.-T.; project administration, Á.V.-O. and A.D.G.-D.; funding acquisition, C.T.-T. All authors have read and agreed to the published version of the manuscript.

Funding: This research received no external funding.

Institutional Review Board Statement: Not applicable.

Informed Consent Statement: Not applicable.

Data Availability Statement: The data presented in this study are available upon request from the corresponding author.

Acknowledgments: The authors would like to acknowledge the Universidad de Cartagena for providing the materials, equipment and time required to conclude this research successfully.

Conflicts of Interest: The authors declare they have no conflicts of interest.

\section{References}

1. Fernando, W.A.M.; Ilankoon, I.M.S.K.; Syed, T.H.; Yellishetty, M. Challenges and opportunities in the removal of sulphate ions in contaminated mine water: A review. Miner. Eng. 2018, 117, 74-90. [CrossRef]

2. Sadeghalvad, B.; Khorshidi, N.; Azadmehr, A.; Sillanpää, M. Sorption, mechanism, and behavior of sulfate on various adsorbents: A critical review. Chemosphere 2021, 263, 128064. [CrossRef] [PubMed]

3. John, Y.; David, V.E.; Mmereki, D. A Comparative Study on Removal of Hazardous Anions from Water by Adsorption: A Review. Int. J. Chem. Eng. 2018, 2018, 1-21. [CrossRef]

4. Sadeghalvad, B.; Azadmehr, A.; Hezarkhani, A. Sulfate decontamination from groundwater by metal layered double hydroxides functionalized high phosphorus iron ore waste as a new green adsorbent: Experimental and modeling. Ecol. Eng. 2017, 106, 219-230. [CrossRef]

5. Rodrigues, C.; Follmann, H.V.D.M.; Núñez-Gómez, D.; Nagel-Hassemer, M.E.; Lapolli, F.R.; Lobo-Recio, M.Á. Sulfate removal from mine-impacted water by electrocoagulation: Statistical study, factorial design, and kinetics. Environ. Sci. Pollut. Res. 2020, 27, 39572-39583. [CrossRef]

6. Tang, W.; He, D.; Zhang, C.; Waite, T.D. Optimization of sulfate removal from brackish water by membrane capacitive deionization (MCDI). Water Res. 2017, 121, 302-310. [CrossRef]

7. Navamani Kartic, D.; Aditya Narayana, B.C.H.; Arivazhagan, M. Removal of high concentration of sulfate from pigment industry effluent by chemical precipitation using barium chloride: RSM and ANN modeling approach. J. Environ. Manag. 2018, 206, 69-76. [CrossRef]

8. Song, W.; Gao, B.; Guo, Y.; Xu, X.; Yue, Q.; Ren, Z. Effective adsorption/desorption of perchlorate from water using corn stalk based modified magnetic biopolymer ion exchange resin. Microporous Mesoporous Mater. 2017, 252, 59-68. [CrossRef]

9. Ao, H.; Cao, W.; Hong, Y.; Wu, J.; Wei, L. Adsorption of sulfate ion from water by zirconium oxide-modified biochar derived from pomelo peel. Sci. Total Environ. 2020, 708, 135092. [CrossRef] 
10. Wang, L.; Xu, Z.; Fu, Y.; Chen, Y.; Pan, Z.; Wang, R.; Tan, Z. Comparative analysis on adsorption properties and mechanisms of nitrate and phosphate by modified corn stalks. RSC Adv. 2018, 8, 36468-36476. [CrossRef]

11. Banu, H.A.T.; Karthikeyan, P.; Meenakshi, S. Comparative studies on revival of nitrate and phosphate ions using quaternized corn husk and jackfruit peel. Bioresour. Technol. Rep. 2019, 8, 100331. [CrossRef]

12. Wei, C.; Huang, Y.; Liao, Q.; Xia, A.; Zhu, X.; Zhu, X. Adsorption thermodynamic characteristics of Chlorella vulgaris with organic polymer adsorbent cationic starch: E ff ect of temperature on adsorption capacity and rate. Bioresour. Technol. 2019, 293, 8. [CrossRef] [PubMed]

13. Fu, W.; Ji, G.; Chen, H.; Yang, S.; Yang, H.; Guo, B.; Huang, Z. Engineering Anion Resin based Amorphous Molybdenum Sulphide Composite for Treatment of Authentic Acid Mine Drainage. J. Environ. Chem. Eng. 2020, 8, 104072. [CrossRef]

14. Fu, W.; Ji, G.; Chen, H.; Yang, S.; Guo, B.; Yang, H.; Huang, Z. Molybdenum sulphide modified chelating resin for toxic metal adsorption from acid mine wastewater. Sep. Purif. Technol. 2020, 215, 117407. [CrossRef]

15. Roohi, R.; Hashemi, S.M.B.; Mousavi Khaneghah, A. Kinetics and thermodynamic modelling of the aflatoxins decontamination: A review. Int. J. Food Sci. Technol. 2020, 55, 3525-3532. [CrossRef]

16. Manjunath, S.V.; Kumar, M. Evaluation of single-component and multi-component adsorption of metronidazole, phosphate and nitrate on activated carbon from Prosopis juliflora. Chem. Eng. J. 2018, 346, 525-534. [CrossRef]

17. Xu, J.; Krietemeyer, E.F.; Boddu, V.M.; Liu, S.X.; Liu, W.C. Production and characterization of cellulose nanofibril (CNF) from agricultural waste corn stover. Carbohydr. Polym. 2018, 192, 202-207. [CrossRef] [PubMed]

18. Xia, F.; Yang, H.; Li, L.; Ren, Y.; Shi, D.; Chai, H.; Ai, H.; He, Q.; Gu, L. Enhanced nitrate adsorption by using cetyltrimethylammonium chloride pre-loaded activated carbon. Environ. Technol. (UK) 2019, 41, 3562-3572. [CrossRef]

19. ASTM, A.S. for T. and M. ASTM D 560-60 Standard Test Method for Sulfate in Brackish Water, Seawater, and Brines; ASTM: West Conshohocken, PA, USA, 2018; pp. 1-5.

20. Dobrosz-Gómez, I.; Gómez, M.; Santa, C. Optimización del Proceso de Adsorción de Cr (VI) sobre Carbón Activado de Origen Bituminoso. Inf. Tecnol. 2018, 29, 43-56. [CrossRef]

21. Hu, Q.; Chen, N.; Feng, C.; Hu, W.; Liu, H. Kinetic and isotherm studies of nitrate adsorption on granular Fe-Zr-chitosan complex and electrochemical reduction of nitrate from the spent regenerant solution. RSC Adv. 2016, 6, 61944-61954. [CrossRef]

22. Sereshti, H.; Zamiri Afsharian, E.; Esmaeili Bidhendi, M.; Rashidi Nodeh, H.; Afzal Kamboh, M.; Yilmaz, M. Removal of phosphate and nitrate ions aqueous using strontium magnetic graphene oxide nanocomposite: Isotherms, kinetics, and thermodynamics studies. Environ. Prog. Sustain. Energy 2020, 39, e13332. [CrossRef]

23. Cao, W.; Dang, Z.; Zhou, X.Q.; Yi, X.Y.; Wu, P.X.; Zhu, N.W.; Lu, G.N. Removal of sulphate from aqueous solution using modified rice straw: Preparation, characterization and adsorption performance. Carbohydr. Polym. 2011, 85, 571-577. [CrossRef]

24. Fan, C.; Zhang, Y. Adsorption isotherms, kinetics and thermodynamics of nitrate and phosphate in binary systems on a novel adsorbent derived from corn stalks. J. Geochem. Explor. 2018, 188, 95-100. [CrossRef]

25. Yousif, A.M.; Atia, A.A.; Zaid, O.F.; Ibrahim, I.A. Efficient and Fast Adsorption of Phosphates and Sulphates on Prepared Modified Cellulose. J. Dispers. Sci. Technol. 2015, 36, 1628-1638. [CrossRef]

26. Mehdinejadiani, B.; Amininasab, S.M.; Manhooei, L. Enhanced adsorption of nitrate from water by modified wheat straw: Equilibrium, kinetic and thermodynamic studies. Water Sci. Technol. 2019, 79, 302-313. [CrossRef]

27. Premkumar, P.; Sudha, R. Comparative studies on the removal of chromium (VI) from aqueous solutions using raw and modified Citrus Limettioides peel. Indian J. Chem. Technol. 2018, 25, 255-265.

28. Yin, Q.; Liu, M.; Ren, H. Biochar produced from the co-pyrolysis of sewage sludge and walnut shell for ammonium and phosphate adsorption from water. J. Environ. Manag. 2019, 249, 109410. [CrossRef]

29. Dong, S.; Ji, Q.; Wang, Y.; Liu, H.; Qu, J. Enhanced phosphate removal using zirconium hydroxide encapsulated in quaternized cellulose. J. Environ. Sci. (China) 2020, 89, 102-122. [CrossRef] [PubMed]

30. Alagha, O.; Manzar, M.S.; Zubair, M.; Anil, I.; Mu'azu, N.D.; Qureshi, A. Comparative adsorptive removal of phosphate and nitrate from wastewater using biochar-MgAl LDH nanocomposites: Coexisting anions effect and mechanistic studies. Nanomaterials 2020, 10, 336. [CrossRef]

31. Golie, W.M.; Upadhyayula, S. An investigation on biosorption of nitrate from water by chitosan based organic-inorganic hybrid biocomposites. Int. J. Biol. Macromol. 2017, 97, 489-502. [CrossRef] [PubMed]

32. Sowmya, A.; Meenakshi, S. A novel quaternized resin with acrylonitrile/divinylbenzene/vinylbenzyl chloride skeleton for the removal of nitrate and phosphate. Chem. Eng. J. 2014, 257, 45-55. [CrossRef]

33. Karthikeyan, P.; Meenakshi, S. Synthesis and characterization of Zn-Al LDHs/activated carbon composite and its adsorption properties for phosphate and nitrate ions in aqueous medium. J. Mol. Liq. 2019, 296, 111766. [CrossRef] 